\title{
Bilateral \\ autoimmune optic neuritis and vitreitis related to CRMP-5- IgG: intravitreal triamcinolone acetonide therapy of four eyes
}

Eye (2009) 23, 1883; doi:10.1038/sj.eye.6703007

Eye (2008) 22, 1191-1193; doi:10.1038/sj.eye.6702959; published online 24 August 2007

Since the publication of the above article, the authors have noticed that one of the author names was missing.
J Pulido, SA Cross, VA Lennon, D Swanson,

$M$ Muench and DH Lachance
The correct list of authors is shown below:

J Pulido, SA Cross, VA Lennon, J Pulido, D Swanson, M Muench and DH Lachance

The typesetters would like to apologise for this mistake. 